\title{
MENSURAÇÃO DA \\ CAPACIDADE DE GERAÇÃO \\ DE ENERGIA ELÉTRICA A \\ PARTIR DO TRATAMENTO \\ DOS DESJETOS SUÍNOS
}

Measurement of electricity generation capacity from treatment of swine dejects

Fabrício Oliveira Leitão

Cleandro Pazinato Dias

Marlon Vinícius Brisola 


\title{
MENSURAĈ̃O DA CAPACIDADE DE GERAÇ̃̃O DE ENERGIA ELÉTRICA A PARTIR DO TRATAMENTO DOS DEJETOS SUÍNOS
}

\author{
Measurement of electricity generation capacity from treatment of swine dejects
}

Fabrício Oliveira Leitão

Cleandro Pazinato Dias

Marlon Vinícius Brisola

\begin{abstract}
Resumo: É cada vez maior a busca de soluções tecnológicas para o aproveitamento dos resíduos da produção com a finalidade de geração de energia. O objetivo do trabalho foi mensurar a capacidade de geração de energia elétrica através do biogás oriundo do tratamento de dejetos suínos, e realizar um estudo de viabilidade econômica de tecnologias na introdução dos três principais sistemas de produção de suínos encontrados no país. Os procedimentos metodológicos foram concebidos através de uma revisão sistemática de literatura, com o auxílio de uma análise de conteúdo e de pesquisas de campo. Como resultados foi observado o grande potencial de geração de energia elétrica em caráter renovável, por meio da utilização do biogás, sendo uma potencial fonte de renda nas propriedades produtoras de suínos. Entretanto, vale ressaltar que são poucos os projetos que apresentaram viabilidade econômica, sendo os de maior escala de produção os que oferecem os melhores resultados.
\end{abstract}

Palavras-chaves: Viabilidade Econômica; Aproveitamento de Resíduos; Energia.

\begin{abstract}
The search for technological solutions for the use of waste from production for the purpose of generating energy is increasing. The objective of this work was to measure the electric power generation capacity through the biogas from the treatment of swine manure, and to carry out an economic feasibility study of technologies in the introduction of the three main systems of production of pigs found in the country. The methodological procedures were designed through a systematic review of the literature, with the aid of content analysis and field research. As results, we observed the great potential of renewable energy generation, through the use of biogas, being a potential source of income in the pork producing properties. However, it is worth mentioning that there are few projects that presented economic viability, the ones with the largest production scale offering the best results.
\end{abstract}

Keywords: Economic Viability; Waste Utilization; Energy.

Resumen: Hay una búsqueda creciente de soluciones tecnológicas para el uso de residuos de producción con el propósito de generar energía. El objetivo de este trabajo fue medir la capacidad de generación de energía eléctrica a través del biogás a partir del tratamiento del estiércol porcino, y llevar a cabo un estudio de viabilidad económica de tecnologías en la introducción de los tres principales sistemas de producción porcina encontrados en el país. Los procedimientos metodológicos fueron concebidos a través de una revisión sistemática de la literatura, con la ayuda de un análisis de contenido y una investigación de campo. Como resultado, se observó el gran potencial de generación de energía renovable mediante el uso de biogás, siendo una fuente potencial de ingresos en las granjas porcinas. Sin embargo, es notable que haya pocos proyectos que presenten viabilidad económica, y aquellos con la escala de producción más grande ofrecen los mejores resultados.

Palabra clave: Viabilidad económica; Recuperación de residuos; Energía. 
IGepec, Toledo, v. 24, n.1, p. 91-115, jan./jun. 2020. 


\section{INTRODUÇÃO}

A produção brasileira de suínos passou por grandes transformações nos últimos 20 anos, resultados do aumento da introdução de novas tecnologias e, consequentemente, da produtividade, sobretudo das escalas de produção, tendo como objetivo principal o aumento da competitividade. Porém, essa atividade é vista como potencialmente poluidora, principalmente em virtude do volume de dejetos gerados.

O aumento da concentração de animais também trouxe desafios relacionados ao meio ambiente no que tange ao tratamento dos efluentes. Grande parte dos investimentos em um sistema de produção de suínos está relacionada à implementação de tecnologias que reduzam o potencial poluidor dos dejetos. Adicionalmente, é cada vez maior a busca de soluções tecnológicas para um aproveitamento econômico dos resíduos dessa produção, como o biofertilizante e, sobretudo, a geração de energia elétrica a partir do biogás gerado a partir do tratamento dos dejetos dos suínos.

Atualmente as técnicas empregadas no tratamento de dejetos de suínos consistem em processos físicos, químicos e biológicos com o intuito de reduzir a carga de poluentes. Além das formas habituais de tratamento e uso dos dejetos, algumas tecnologias estão menos difundidas ou em fase de pesquisa, mas podem contribuir para a redução das emissões de gases de efeito estufa.

O impacto gerado pelo aumento do volume de dejetos pode ser mitigado pela adoção de métodos de processamento, como a biodigestão, através da utilização de biodigestores. Trata-se de um processo fermentativo anaeróbio e controlado, formando uma massa microbiológica estável e gases como produto desses microrganismos. Os principais gases formados são o dióxido de carbono (CO2), o metano $\left(\mathrm{CH}_{4}\right)$, o óxido nitroso $(\mathrm{N} 2 \mathrm{O})$ e o gás sulfídrico $(\mathrm{H} 2 \mathrm{~S})$, sendo que o $\mathrm{CH}_{4}$ e o $\mathrm{N} 2 \mathrm{O}$ são queimados e transformados em $\mathrm{CO}_{2}$ e N2, contribuindo para a redução do aquecimento global.

Os modelos de produção sustentáveis conduzem mudanças nos sistemas tradicionais de produção de suínos, além de proporcionarem incrementos de lucro à atividade através da geração de biogás e posterior conversão em energia.

Estudos recentes apontam a produção animal como uma das principais emissoras de Gases de Efeito Estufa (GEE), motivando movimentos populares para a redução e exclusão do consumo de carne. A pecuária é responsável por grande parte da emissão de GEE, sendo que 9\% é atribuído à produção de suínos (GERBER, et al., 2013). Uma produção sustentável de carne suína nos remete a utilização de mecanismos que minimizem este impacto.

Nos sistemas de criação de suínos no Brasil, o gasto com energia elétrica corresponde, em média, 3,98\% dos custos totais de produção (CONAB, 2014). Em estados como o de Minas Gerais, por exemplo, em que existe maior incidência de tributos sobre a energia elétrica, esse percentual chega a 7,43\% (CONAB, 2014).

A inclusão de fontes renováveis de energia no ambiente industrial e residencial do Brasil é pauta de discussões e de preocupação há anos. Na década de 80, a Comissão Nacional de Energia já ressaltava que ações vigorosas voltadas para a substituição da eletricidade por outras formas de energia renováveis, bem como para a redução de desperdícios através de medidas conservacionistas deveriam iniciar imediatamente. A utilização do gás natural e do biogás recebeu destaque nesse sentido (LEITE; SOUZA, 2015).

Decisões para mitigar os efeitos nocivos da produção que causam impacto ambiental devem ser tomadas para que possa trazer sustentabilidade para os sistemas produtivos, notadamente para aqueles que mais agridem o meio ambiente, como a produção de suínos (LEITÂO; SILVA, 2018). 
Em 2002, a ANEEL (Agência Nacional de Energia Elétrica) introduziu um novo cenário para a geração de energia elétrica a partir do biogás com saneamento ambiental através da reforma do PRODIST (Procedimentos de Distribuição de Energia Elétrica no Sistema Elétrico Nacional). A Agência publicou a Instrução Normativa 390/o9, que se refere exclusivamente à Geração Distribuída com Biogás e saneamento ambiental (BRASIL, 2002).

A Resolução Normativa 482 da ANEEL, de abril de 2012, estabelece as condições gerais para micro geração e mini geração distribuída, bem como o sistema de compensação de energia elétrica (ANEEL, 2012). Segundo as novas regras, é permitido o uso de qualquer fonte renovável, além da cogeração qualificada, denominando-se microgeração distribuída. Quando a quantidade de energia gerada em determinado mês for superior à energia consumida naquele período, o consumidor fica com créditos que podem ser utilizados para diminuir a fatura dos meses seguintes. Esse crédito de energia elétrica poderá ser utilizado pela própria unidade geradora em épocas de alto consumo (acima da geração) ou em outras unidades consumidoras cadastradas no mesmo CPF ou CNPJ que consumam energia da mesma concessionária (ANELL, 2012).

Ainda que se conheçam as especificidades impostas pela ANEEL acerca do uso e da distribuição da energia elétrica produzida a partir dos dejetos suínos, é superficial o conhecimento da quantidade de KW/h (Quilowatt-hora) que é possível produzir, considerando o plantel de animais que constituem a cadeia de suínos no Brasil. Neste cenário, o biogás surge como uma alternativa para a inclusão de fontes renováveis de energia na matriz energética brasileira.

O objetivo do trabalho foi mensurar a capacidade de geração de energia elétrica através do biogás oriundo do tratamento de dejetos suínos, bem como realizar um estudo de viabilidade econômica da introdução dos três principais sistemas de produção de suínos encontrados no país: Unidades de Ciclo Completo (CC), Unidades Produtoras de Leitões (UPL) e Unidades Terminadoras (UT).

Importante ressaltar que o levantamento da capacidade de geração de energia elétrica a partir dos dejetos de suínos ajuda a fundamentar a tomada de decisão dos agentes econômicos e governamentais no que tange ao incentivo da produção da energia a partir de fontes renováveis.

Para complementar o estudo, com as informações levantadas sobre o potencial de geração de energia elétrica a partir dos dejetos suínos, foi possível saber quantas residências populares poderiam ser abastecidas no Brasil somente com a produção destes e, a partir daí incentivar a produção de biogás. Essa pode ser uma fonte alternativa para geração de energia elétrica para nosso país, principalmente em épocas de crise energética, como tem acontecido nos últimos anos.

\section{MATERIAL E MÉTODOS 2.1 Mensuração da capacidade de geração de energia elétrica}

Do ponto de vista de sua natureza, esta pesquisa é classificada como básica. Com relação aos seus objetivos, como exploratória-descritiva. No que tange à forma de abordagem do problema, quali-quantitativa. Do ponto de vista dos procedimentos técnicos, foi baseada em uma Revisão Sistemática da Literatura (RSL).

Em termos metodológicos, o potencial energético da suinocultura brasileira foi analisado a partir da mensuração do total de efluentes gerados pelos sistemas de produção de suínos e do biogás gerado com a instalação de biodigestores.

Para tanto, foi levantado o número de matrizes suína em ciclo completo, que de acordo com Souza et. al. (2004) gera 72 litros de dejetos/dia, com potencial de 
geração de biogás é de $0,775 \mathrm{~m}^{3} /$ dia. O poder calorífico do biogás é de $6,5 \mathrm{KWh} / \mathrm{m}^{3} \mathrm{e}$ a eficiência de conversão do biogás em energia elétrica com grupos geradores (motores ciclo Otto) é de aproximadamente $25 \%$ (CCE, 2010).

Em posse dos dados referente ao rebanho de matrizes suínas no Brasil, foi possível mensurar o volume total de dejetos gerados por dia. Destarte, foi calculado o valor em metros cúbicos, e o mesmo foi multiplicado pelo valor correspondente a potência de geração de biogás $(0,775)$. Com os valores, foi possível quantificar a produção de biogás por hora (dividindo o valor por 24). Por fim, para mensurar a produção de energia em $\mathrm{KW} / \mathrm{h}$, foi feito um cálculo multiplicando o valor encontrado por $1,625,\left(6,5 \mathrm{KWh} / \mathrm{m}^{3} \times \mathrm{x}, 25 \%\right)$. De tal forma, foi encontrado o valor referente ao potencial de geração de energia elétrica a partir do tratamento dos dejetos suínos e posterior utilização do biogás.

Considerando que, de acordo com dados da Empresa de Pesquisa Energética - EPE, uma residência popular consome em média $75 \mathrm{KW} / \mathrm{h}$, com base no ano de 2018 , foi possível determinar a quantidade de residências com possibilidade de atendimento a partir da energia gerada (EPE, 2019). A EPE ainda afirma que o consumo total de energia elétrica do setor residencial crescerá 48\% entre 2017 e 2027 (EPE, 2019).

Além disso, foram realizados levantamentos primários junto a duas empresas produtoras de motores que transformam o biogás em energia elétrica, através de entrevistas com representantes escolhidos de forma intencional para levantar o potencial de energia elétrica produzida por motor. Uma empresa quis se identificar, a ER-BR, a outra não.

O procedimento técnico adotado foi concebido como uma RSL. Essa buscou a identificação, análise e compilação de dados e informações cuja temática envolvesse a mensuração da capacidade de geração de energia elétrica a partir do tratamento de dejetos suínos oriundos da suinocultura brasileira a partir de uma abordagem exploratória-descritiva.

A RSL foi seguida utilizando o protocolo proposto por Cronin, Ryan \& Coughlan (2008). Os resultados encontrados foram analisados através da técnica de análise de conteúdo, proposta por Bardin (1997). A análise de conteúdo foi operacionalizada mediante os dados coletados na RSL. A lógica de aplicação desse método de análise recai sobre a importância de se estabelecer categorias de análises para os dados coletados, que são de natureza essencialmente qualitativa.

O método de análise de conteúdo deste trabalho compreendeu as seguintes fases: I) Leitura do material coletado, neste caso os artigos levantados nas buscas realizadas; II) Codificação para formulação de categorias de análise; III) Recorte do material (em unidades de registro, como palavras, frases e parágrafos, comparáveis e com o mesmo conteúdo semântico); IV) Estabelecimento de categorias (diferente, tematicamente, das unidades de registro; V) Agrupamento das unidades de registro em categorias comuns; VI) Agrupamento progressivo das categorias (iniciais, intermediárias e finais, respectivamente); e VII) Inferência e interpretação (BARDIN, 1977). 


\subsection{Estudo de viabilidade econômica}

Para a análise dos cálculos da viabilidade econômica foram levadas em consideração as tecnologias relacionadas à biodigestão com o aproveitamento do biogás para produção de energia elétrica por meio de geradores e compostagem. Ambos processos podem ser teoricamente implantados em qualquer região produtora de suínos do Brasil, sendo a escolha da melhor opção para cada propriedade um exercício técnico/econômico particular que cada unidade deve fazer, considerando as peculiaridades de cada uma.

Para as projeções da biodigestão considerou-se três simulações, uma com a utilização de geração distribuída, outra sem geração distribuída considerando a utilização de biodigestor e grupo gerador com base na produção de biogás máxima das granjas, e a terceira com biodigestor e grupo gerador dimensionados para a demanda energética das granjas, considerando apenas a suinocultura.

Os custos para implantação e manutenção das diferentes etapas tecnológicas utilizadas nos estudos são uma média nacional dos valores praticados no mercado por empresas de referência que operam no setor de tratamento de dejetos, levantados em 2018.

Para que o estudo de viabilidade pudesse contemplar o maior número de propriedades, o mesmo foi elaborado para os três principais sistemas de produção de suínos encontrados no Brasil: Unidades de Ciclo Completo (CC), Unidades Produtoras de Leitões (UPL) e Unidades Terminadoras (UT). Além disso, com relação a escala de produção, foram definidos três tamanhos: Pequeno, Médio e Grande (Tabela 1).

Tabela 1 - Sistemas de produção e escalas produtivas das tecnologias redutoras de gases de efeito estufa associadas ao tratamento de dejetos suínos

\begin{tabular}{|c|c|c|c|c|c|c|c|c|c|}
\hline \multirow{2}{*}{$\begin{array}{c}\text { SISTEMA } \\
\text { DE } \\
\text { PRODUCÃO }\end{array}$} & \multicolumn{3}{|c|}{ Ciclo Completo } & \multicolumn{3}{|c|}{ UPL } & \multicolumn{3}{|c|}{ UT } \\
\hline & Peq. & Médio & Grande & Peq. & Médio & Grande & Peq. & Médio & Grande \\
\hline $\begin{array}{c}\mathrm{N}^{\mathrm{o}} \mathrm{de} \\
\text { matrizes }\end{array}$ & 250 & 500 & 1.000 & 500 & 1.000 & 2.000 & - & - & - \\
\hline $\begin{array}{c}\mathrm{N}^{\mathrm{o}} \mathrm{de} \\
\text { animais na } \\
\text { engorda }\end{array}$ & - & - & - & - & - & - & 500 & 1.500 & 4.000 \\
\hline
\end{tabular}

A combinação dos três sistemas de produção, com as três escalas produtivas, os dois processos tecnológicos (compostagem e biodigestão), e os três tipos de simulação da biodigestão, permitiu elaborar 36 projetos para o estudo de viabilidade (Tabela 2 ).

Tabela 2 - Lista dos 36 projetos elaborados

\begin{tabular}{|c|c|c|c|}
\hline $\mathbf{N}^{\mathbf{O}}$ & $\begin{array}{c}\text { Projeto } \\
\end{array}$ & Escala & Produto Base \\
\hline 1 & $\begin{array}{c}\text { Biodigestor - Ciclo Completo } 250 \text { matrizes - } \\
\text { Geração Distribuída }\end{array}$ & 250 matrizes & $\begin{array}{l}\text { Energia elétrica- geração } \\
\text { distribuída }\end{array}$ \\
\hline 2 & $\begin{array}{c}\text { Biodigestor - Ciclo Completo 250 matrizes - } \\
\text { Sem Geração Distribuída }\end{array}$ & 250 matrizes & Energia elétrica \\
\hline 3 & $\begin{array}{c}\text { Biodigestor - Ciclo Completo } 250 \text { matrizes - } \\
\text { Consumo Próprio }\end{array}$ & 250 matrizes & Energia elétrica \\
\hline 4 & Compostagem - Ciclo Completo 250 matrizes & 250 matrizes & Composto orgânico \\
\hline 5 & $\begin{array}{c}\text { Biodigestor - Ciclo Completo 500 matrizes - } \\
\text { Geração Distribuída }\end{array}$ & 500 matrizes & $\begin{array}{l}\text { Energia elétrica- geração } \\
\text { distribuída }\end{array}$ \\
\hline 6 & $\begin{array}{l}\text { Biodigestor - Ciclo Completo } 500 \text { matrizes - } \\
\text { Sem Geração Distribuída }\end{array}$ & 500 matrizes & Energia elétrica \\
\hline 7 & $\begin{array}{c}\text { Biodigestor - Ciclo Completo } 500 \text { matrizes - } \\
\text { Consumo Próprio }\end{array}$ & 500 matrizes & Energia elétrica \\
\hline
\end{tabular}




\begin{tabular}{|c|c|c|c|}
\hline 8 & Compostagem - Ciclo Completo 500 matrizes & 500 matrizes & Composto orgânico \\
\hline 9 & $\begin{array}{c}\text { Biodigestor - Ciclo Completo 1000 matrizes - } \\
\text { Geração Distribuída }\end{array}$ & $\begin{array}{c}1000 \\
\text { matrizes }\end{array}$ & $\begin{array}{c}\text { Energia elétrica- geração } \\
\text { distribuída }\end{array}$ \\
\hline 10 & $\begin{array}{c}\text { Biodigestor - Ciclo Completo 100o matrizes - } \\
\text { Sem Geração Distribuída }\end{array}$ & $\begin{array}{c}1000 \\
\text { matrizes }\end{array}$ & Energia elétrica \\
\hline 11 & $\begin{array}{c}\text { Biodigestor - Ciclo Completo } 1000 \text { matrizes - } \\
\text { Consumo Próprio }\end{array}$ & $\begin{array}{c}1000 \\
\text { matrizes }\end{array}$ & Energia elétrica \\
\hline 12 & Compostagem - Ciclo Completo 1000 matrizes & $\begin{array}{c}1000 \\
\text { matrizes }\end{array}$ & Composto orgânico \\
\hline 13 & $\begin{array}{c}\text { Biodigestor - UPL 500 matrizes - Geração } \\
\text { Distribuída }\end{array}$ & 500 matrizes & $\begin{array}{c}\text { Energia elétrica- geração } \\
\text { distribuída }\end{array}$ \\
\hline 14 & $\begin{array}{c}\text { Biodigestor - UPL 500 matrizes - Sem Geração } \\
\text { Distribuída }\end{array}$ & 500 matrizes & Energia elétrica \\
\hline 15 & $\begin{array}{c}\text { Biodigestor - UPL } 500 \text { matrizes - Consumo } \\
\text { Próprio }\end{array}$ & 500 matrizes & Energia elétrica \\
\hline 16 & Compostagem - UPL 500 matrizes & 500 matrizes & Composto orgânico \\
\hline 17 & $\begin{array}{c}\text { Biodigestor - UPL 100O matrizes - Geração } \\
\text { Distribuída }\end{array}$ & $\begin{array}{c}1000 \\
\text { matrizes }\end{array}$ & $\begin{array}{c}\text { Energia elétrica- geração } \\
\text { distribuída }\end{array}$ \\
\hline 18 & $\begin{array}{c}\text { Biodigestor - UPL 1000 matrizes - Sem Geração } \\
\text { Distribuída }\end{array}$ & $\begin{array}{c}1000 \\
\text { matrizes }\end{array}$ & Energia elétrica \\
\hline 19 & $\begin{array}{c}\text { Biodigestor - UPL 1000 matrizes - Consumo } \\
\text { Próprio }\end{array}$ & $\begin{array}{c}1000 \\
\text { matrizes }\end{array}$ & Energia elétrica \\
\hline 20 & Compostagem - UPL 1000 matrizes & $\begin{array}{c}1000 \\
\text { matrizes }\end{array}$ & Composto orgânico \\
\hline 21 & $\begin{array}{c}\text { Biodigestor - UPL } 2000 \text { matrizes - Geração } \\
\text { Distribuída }\end{array}$ & $\begin{array}{c}2000 \\
\text { matrizes }\end{array}$ & $\begin{array}{c}\text { Energia elétrica- geração } \\
\text { distribuída }\end{array}$ \\
\hline 22 & $\begin{array}{c}\text { Biodigestor - UPL 200O matrizes - Sem Geração } \\
\text { Distribuída }\end{array}$ & $\begin{array}{c}2000 \\
\text { matrizes }\end{array}$ & Energia elétrica \\
\hline 23 & $\begin{array}{c}\text { Biodigestor - UPL 2000 matrizes - Consumo } \\
\text { Próprio } \\
\end{array}$ & $\begin{array}{l}2000 \\
\text { matrizes }\end{array}$ & Energia elétrica \\
\hline 24 & Compostagem - UPL 2000 matrizes & $\begin{array}{c}2000 \\
\text { matrizes }\end{array}$ & Composto orgânico \\
\hline 25 & $\begin{array}{l}\text { Biodigestor - Unidade de Terminação } 500 \\
\text { animais - Geração Distribuída }\end{array}$ & 500 animais & $\begin{array}{l}\text { Energia elétrica- geração } \\
\text { distribuída }\end{array}$ \\
\hline 26 & $\begin{array}{l}\text { Biodigestor - Unidade de Terminação } 500 \\
\text { animais - Sem Geração Distribuída }\end{array}$ & 500 animais & Energia elétrica \\
\hline 27 & $\begin{array}{c}\text { Biodigestor - Unidade de Terminação } 500 \\
\text { animais - Consumo Próprio }\end{array}$ & 500 animais & Energia elétrica \\
\hline 28 & $\begin{array}{c}\text { Compostagem - Unidade de Terminação } 500 \\
\text { animais }\end{array}$ & 500 animais & Composto orgânico \\
\hline 29 & $\begin{array}{c}\text { Biodigestor - Unidade de Terminação } 1500 \\
\text { animais - Geração Distribuída }\end{array}$ & 1500 animais & $\begin{array}{c}\text { Energia elétrica- geração } \\
\text { distribuída }\end{array}$ \\
\hline 30 & $\begin{array}{l}\text { Biodigestor - Unidade de Terminação } 1500 \\
\text { animais - Sem Geração Distribuída }\end{array}$ & 1500 animais & Energia elétrica \\
\hline 31 & $\begin{array}{c}\text { Biodigestor - Unidade de Terminação } 1500 \\
\text { animais - Consumo Próprio }\end{array}$ & 1500 animais & Energia elétrica \\
\hline 32 & $\begin{array}{c}\text { Compostagem - Unidade de Terminação } 1500 \\
\text { animais }\end{array}$ & 1500 animais & Composto orgânico \\
\hline 33 & $\begin{array}{c}\text { Biodigestor - Unidade de Terminação } 4000 \\
\text { animais - Geração Distribuída }\end{array}$ & $\begin{array}{c}4000 \\
\text { animais }\end{array}$ & $\begin{array}{l}\text { Energia elétrica- geração } \\
\text { distribuída }\end{array}$ \\
\hline 34 & $\begin{array}{l}\text { Biodigestor - Unidade de Terminação } 4000 \\
\text { animais - Sem Geração Distribuída }\end{array}$ & $\begin{array}{c}4000 \\
\text { animais }\end{array}$ & Energia elétrica \\
\hline 35 & $\begin{array}{c}\text { Biodigestor - Unidade de Terminação } 4000 \\
\text { animais - Consumo Próprio }\end{array}$ & $\begin{array}{c}4000 \\
\text { animais }\end{array}$ & Energia elétrica \\
\hline 36 & $\begin{array}{c}\text { Compostagem - Unidade de Terminação } 4000 \\
\text { animais }\end{array}$ & $\begin{array}{c}4000 \\
\text { animais }\end{array}$ & Composto orgânico \\
\hline
\end{tabular}


Todos estudos partiram do pressuposto que as granjas já estavam em operação, ou seja, as etapas anteriores a produção dos dejetos não foram consideradas nos cálculos.

As análises econômicas foram realizadas com base nos indicadores TIR, VPL e PayBack.

O estudo utilizou as seguintes condições como premissas para viabilizar a implantação das tecnologias de tratamento de dejetos suínos:

- $\quad$ Taxa de 7,5\% ao ano considerando que pelo montante financiado nos projetos os produtores se enquadrariam como beneficiários do Pronamp;

- Financiamento de $100 \%$ do valor dos investimentos, observando o limite de até R\$ 2 milhões por cliente, por ano safra; e

- $\quad$ Prazo de até 10 anos, incluindo carência de até 5 anos.

As projeções contemplaram um fluxo de caixa (prazo) para a análise de 10 anos. A taxa mínima de atratividade utilizada para cálculo do VPL foi de 7,5\% ao ano. As premissas gerais adotadas visando permitir as análises foram:

- Os valores dos materiais e equipamentos utilizados no estudo são uma média nacional de preços praticados por empresas de referência, sendo o frete por conta do comprador (frete FOB);

- $\quad$ O custo por $\mathrm{kWh}$ da energia elétrica utilizado nos estudos (biodigestão e compostagem) foi padronizado, considerando a média do valor dos estados de Mato Grosso, Minas Gerais, Rio Grande do Sul e Santa Catarina. O valor adotado foi de R\$ o,36; e

- $\quad$ Os valores de mão de obra utilizados tomam como referência o salário mínimo nacional.

\subsubsection{Análise de viabilidade econômica - biodigestor}

Para os projetos de biodigestão adotou-se:

- A estimativa de produção de biogás ( $\mathrm{m}^{3} /$ animal) utilizada no estudo é a praticada pelas empresas que fornecem tecnologia para este segmento, e presume que o biodigestor esteja em boas condições e com um adequado manejo dos dejetos;

- $\quad$ Para o estudo foi utilizado a concentração de 65\% de metano no biogás;

- No estudo da viabilidade optou-se por trabalhar com três tipos de simulação:

○ Geração Distribuída, o que permite que o crédito do excedente de energia elétrica produzido na unidade de suínos seja utilizado para deduzir as despesas em outras contas de energia da mesma concessionária e com o mesmo CPF ou CNPJ. Nesse caso consideração da produção de energia elétrica com base na capacidade máxima de produção de biogás das granjas;

○ Sem Geração Distribuída, quando o suinocultor investe objetivando a sua autossuficiência energética. Nesse caso consideração da produção de energia elétrica com base na capacidade máxima de produção de biogás das granjas, assumindo que esse seria o gasto dessas; e

- Consumo Próprio, no qual com base na demanda energética mensal das granjas (Tabela 3), utilizam-se grupos geradores e biodigestores de menor porte, ou seja, não ocorre o aproveitamento da capacidade máxima de produção de biogás das unidades de produção, mas o suficiente para atender sua demanda. 
Tabela 3 - Demandas energéticas mensais das projeções de consumo

\begin{tabular}{c|c}
\hline $\mathbf{N}^{\circ}$ de Animais & $\begin{array}{c}\text { KWh por } \\
\text { mês }\end{array}$ \\
\hline \multicolumn{2}{c}{ Ciclo Completo }
\end{tabular}

\begin{tabular}{c|c}
\hline 250,00 & $5.000,00$ \\
\hline 500,00 & $10.000,00$ \\
\hline 1000,00 & $20.000,00$ \\
\hline
\end{tabular}

Leitões

\begin{tabular}{c|c}
\hline 250,00 & $5.000,00$ \\
\hline 500,00 & $10.000,00$ \\
\hline 2000,00 & $20.000,00$ \\
\hline \multicolumn{2}{l}{ Unidade de Terminação }
\end{tabular}

\begin{tabular}{c|c}
\hline 500,00 & $1.000,00$ \\
\hline 1500,00 & $3.000,00$ \\
\hline 4000,00 & $8.000,00$ \\
\hline
\end{tabular}

OBS: Valores da demanda de kWh por mês determinados por meio de média dos valores de gasto observados junto a granjas questionadas. Como resultado determinou-se a demanda energética baseada em $20 \mathrm{kWh} /$ mês por matriz no ciclo completo, $10 \mathrm{kWh} /$ mês por matriz na unidade de produção de leitões e $2 \mathrm{kWh} /$ mês por suíno na unidade de terminação. Vale destacar que esses valores foram definidos com base em uma pequena amostragem de granjas brasileiras.

- Para as projeções de consumo próprio adotou-se uma demanda energética média (para dimensionamentos), não considerando que ocorre uma demanda oscilante em granjas.

- $\quad$ No custo hora de manutenção é considerado a mão de obra para operar o sistema, incluindo o treinamento de pessoal para operar o sistema, as EPIs utilizadas por este operador, os gastos com óleos lubrificantes para motor e todas as peças de reposição que na medida se desgastam devem ser substituídas.

Para as projeções foram considerados os biodigestores e geradores apresentados na Tabela 4 para os projetos de geração distribuída e sem geração distribuída, e na

Tabela 5 para as projeções de consumo próprio. 
Tabela 4 - Biodigestores e geradores utilizados nos diferentes sistemas de produção para os projetos de geração distribuída e sem geração distribuída

\begin{tabular}{|c|c|c|c|c|c|c|c|c|c|}
\hline \multirow[b]{2}{*}{$\begin{array}{c}\text { SISTE } \\
\text { MA } \\
\text { DE } \\
\text { PROD } \\
\text { UÇÃO }\end{array}$} & \multicolumn{3}{|c|}{ Ciclo Completo } & \multicolumn{3}{|c|}{ UPL } & \multicolumn{3}{|c|}{ UT } \\
\hline & Peq. & Médio & $\begin{array}{c}\text { Grand } \\
\text { e }\end{array}$ & Peq. & Médio & $\begin{array}{c}\text { Grand } \\
\text { e }\end{array}$ & Peq. & Médio & $\begin{array}{c}\text { Grand } \\
\text { e }\end{array}$ \\
\hline $\begin{array}{l}\mathrm{N}^{\circ} \mathrm{de} \\
\text { matriz } \\
\text { es }\end{array}$ & 250 & 500 & 1.000 & 500 & 1.000 & 2.000 & - & - & - \\
\hline $\begin{array}{l}\mathrm{N}^{0} \mathrm{de} \\
\text { animai } \\
\text { s na } \\
\text { engord } \\
\text { a }\end{array}$ & - & - & - & - & - & - & 500 & 1.500 & 4.000 \\
\hline $\begin{array}{c}\text { Investi } \\
\text { mento } \\
\text { biodige } \\
\text { stor } \\
\end{array}$ & $\begin{array}{l}\mathrm{R} \$ 230 . \\
000,00\end{array}$ & $\begin{array}{l}\text { R } \$ 290 . \\
\text { ooo,oo }\end{array}$ & $\begin{array}{l}\mathrm{R} \$ 380 . \\
000,00\end{array}$ & $\begin{array}{l}\mathrm{R} \$ 200 . \\
000,00\end{array}$ & $\begin{array}{l}\mathrm{R} \$ 250 . \\
000,00\end{array}$ & $\begin{array}{l}\mathrm{R} \$ 350 . \\
000,00\end{array}$ & $\begin{array}{l}\mathrm{R} \$ 105 . \\
000,00\end{array}$ & $\begin{array}{l}\mathrm{R} \$ 190 . \\
000,00\end{array}$ & $\begin{array}{l}\mathrm{R} \$ 270 . \\
000,00\end{array}$ \\
\hline $\begin{array}{c}\text { Taman } \\
\text { ho do } \\
\text { biodige } \\
\text { stor } \\
\left(\mathrm{m}^{3}\right)\end{array}$ & 1.200 & 2.200 & 4.000 & 800 & 1.700 & 3.000 & 250 & 700 & 2.000 \\
\hline $\begin{array}{c}\text { Gerado } \\
\text { r } \\
\text { utiliza } \\
\text { do }\end{array}$ & 50KVA & 80KVA & $\begin{array}{c}120 K V \\
A\end{array}$ & 8oKVA & $\begin{array}{c}120 \mathrm{KV} \\
\mathrm{A}\end{array}$ & $\begin{array}{c}330 \mathrm{KV} \\
\mathrm{A}\end{array}$ & 30KVA & $50 \mathrm{KVA}$ & $\begin{array}{c}120 \mathrm{KV} \\
\mathrm{A}\end{array}$ \\
\hline
\end{tabular}

Tabela 5 - Biodigestores e geradores utilizados nos diferentes sistemas de produção para os projetos de consumo próprio

\begin{tabular}{|c|c|c|c|c|c|c|c|c|c|}
\hline \multirow{2}{*}{$\begin{array}{l}\text { SISTE } \\
\text { MA DE } \\
\text { PROD } \\
\text { UCCÃO }\end{array}$} & \multicolumn{3}{|c|}{ Ciclo Completo } & \multicolumn{3}{|c|}{ UPL } & \multicolumn{3}{|c|}{ U'T } \\
\hline & Peq. & Médio & $\begin{array}{c}\text { Grand } \\
\mathbf{e}\end{array}$ & Peq. & Médio & $\begin{array}{c}\text { Grand } \\
\text { e }\end{array}$ & Peq. & $\begin{array}{c}\text { Médi } \\
\text { o }\end{array}$ & $\begin{array}{c}\text { Grand } \\
\text { e }\end{array}$ \\
\hline $\begin{array}{c}\mathrm{N}^{\mathrm{o}} \mathrm{de} \\
\text { matrizes }\end{array}$ & 250 & 500 & 1.000 & 500 & 1.000 & 2.000 & - & - & - \\
\hline $\begin{array}{c}\mathrm{N}^{\circ} \mathrm{de} \\
\text { animais } \\
\text { na } \\
\text { engorda }\end{array}$ & - & - & - & - & - & - & 500 & 1.500 & 4.000 \\
\hline $\begin{array}{l}\text { Investi } \\
\text { mento } \\
\text { biodiges } \\
\text { tor }\end{array}$ & $\begin{array}{c}\mathrm{R} \$ 29.0 \\
91,18\end{array}$ & $\begin{array}{c}\mathrm{R} \$ 58.1 \\
82,35\end{array}$ & $\begin{array}{c}\mathrm{R} \$ 116.3 \\
64,71\end{array}$ & $\begin{array}{c}\mathrm{R} \$ 21.7 \\
63,64\end{array}$ & $\begin{array}{c}\mathrm{R} \$ 43.5 \\
27,27\end{array}$ & $\begin{array}{c}\mathrm{R} \$ 87.0 \\
54,55\end{array}$ & $\begin{array}{l}\mathrm{R} \$ 1.9 \\
89,47\end{array}$ & $\begin{array}{l}\mathrm{R} \$ 5.9 \\
68,42\end{array}$ & $\begin{array}{c}\mathrm{R} \$ 15 \cdot 9 \\
15,79\end{array}$ \\
\hline $\begin{array}{l}\text { Tamanh } \\
\text { o do } \\
\text { biodiges } \\
\text { tor }\left(\mathrm{m}^{3}\right)\end{array}$ & 69,26 & 138,56 & 277,06 & 51,82 & 103,64 & 207,27 & 4,74 & 14,21 & 37,89 \\
\hline $\begin{array}{l}\text { Gerador } \\
\text { utilizado }\end{array}$ & $15 \mathrm{KVA}$ & $15 \mathrm{KVA}$ & $\begin{array}{c}2 \times 15 \mathrm{KV} \\
\mathrm{A}\end{array}$ & $15 \mathrm{KVA}$ & $15 \mathrm{KVA}$ & $\begin{array}{c}2 \times 15 \mathrm{KV} \\
\mathrm{A}\end{array}$ & $15 \mathrm{KVA}$ & $15 \mathrm{KVA}$ & 15KVA \\
\hline
\end{tabular}

OBS: Vale destacar que no mercado brasileiro existe uma grande carência de empresas fabricantes de geradores de "pequeno porte" (menores que $30 \mathrm{kVa}$ ). 


\subsubsection{Análise de viabilidade econômica - compostagem}

Para os projetos de compostagem adotou-se:

- $\quad$ No estudo de viabilidade da compostagem foi utilizado a relação de 10 litros de efluente bruto para cada $1 \mathrm{~kg}$ de substrato (serragem e/ou maravalha) e três lotes no período de um ano;

- $\quad$ Definiu-se que o valor de mercado por tonelada de composto é de $\mathrm{R} \$$ 220,00, tomando-se como base o seu potencial agronômico. Entendemos que este valor é razoável/modesto diante dos preços praticados por outros compostos orgânicos como a cama de frango. Salientamos que o composto oriundo do tratamento dos dejetos suínos apresenta vantagens em relação a cama de frango por não apresentar mal cheiro o que permite a comercialização/uso deste como condicionador de solo em jardinagem; e

Os impostos considerados nas projeções foram:

- IRPF (Imposto de Renda Pessoa Física) - utilizando-se a opção de taxar 20\% sobre a receita bruta, quando for a opção de menor tributação:

- Funrural - 2,1 \% Sobre Receita Bruta;

- Taxa SENAR - 0,2\% sobre a Receita bruta;

- ICMS - Regime diferido (indústria arca com o pagamento).

O próximo capítulo se debruça sobre a discussão dos resultados encontrados no presente trabalho.

\section{Resultados e discussões}

3.1 Resultados da busca inicial dos artigos

Com base no protocolo de RSL, o resultado da busca inicial dos trabalhos com o uso dos construtos supracitados está descrito na Tabela 6. Foram encontrados 185 trabalhos. Todavia, para que estes, de fato, retratem o tema investigado, foram aplicados os critérios de exclusão/inclusão expressos na etapa 2 da revisão sistemática, perfazendo um total de 170 artigos excluídos. De tal modo, ao final da etapa de exclusão/inclusão, restaram apenas 15 (quinze) trabalhos, que atendiam plenamente a pergunta de pesquisa definida na etapa 1 do protocolo, que foram analisados e discutidos na próxima seção.

Tabela 6 - Quantitativo de trabalhos encontrados e respectivos construtos utilizados

\begin{tabular}{|c|c|c|c|c|c|c|}
\hline \multirow[b]{2}{*}{$\begin{array}{l}\mathbf{I} \\
\mathbf{D}\end{array}$} & \multirow[b]{2}{*}{$\begin{array}{c}\text { Descritor } \\
\text { utilizado }\end{array}$} & \multirow[b]{2}{*}{$\begin{array}{c}\text { Bibliote } \\
\text { ca } \\
\text { digital }\end{array}$} & \multicolumn{3}{|c|}{ Base de Dados } & \multirow[b]{2}{*}{$\begin{array}{c}\text { Tota } \\
1\end{array}$} \\
\hline & & & $\begin{array}{c}\text { Google } \\
\text { acadêmi } \\
\text { co }\end{array}$ & $\begin{array}{c}\text { B. Dados } \\
\text { universidad } \\
\text { es }\end{array}$ & $\begin{array}{c}\text { Embra } \\
\text { pa }\end{array}$ & \\
\hline 1 & $\begin{array}{l}\text { Suinocultura e } \\
\text { energia } \\
\text { elétrica }\end{array}$ & 18 & 47 & 6 & 4 & 78 \\
\hline 2 & $\begin{array}{l}\text { Dejetos suínos } \\
\text { e energia } \\
\text { elétrica }\end{array}$ & 9 & 32 & 12 & $\mathrm{O}$ & 53 \\
\hline 3 & $\begin{array}{l}\text { Sustentabilida } \\
\text { de } \\
\text { e energética } \\
\text { suínos }\end{array}$ & $\mathrm{O}$ & 45 & 7 & 2 & 54 \\
\hline
\end{tabular}


Total

27

124

28

6

185

No que tange às publicações científicas brasileiras que abordaram o tema desse trabalho, verificou-se que existe um número pouco expressivo, considerando o horizonte de tempo analisado (2002-2018). É possível afirmar que o assunto é relativamente recente, apesar do grande apelo do impacto ambiental gerado pela criação de suínos. De toda sorte, são apresentadas alternativas para a solução do problema.

3.2 Potencial energético dos dejetos de suínos em biogás - RSL

Segundo Lima (2007) os biodigestores são estruturas hermeticamente fechadas nas quais podem ser acumuladas grandes quantidades de dejetos orgânicos que, por digestão anaeróbica, produzem biogás. O biogás contém compostos simples como o metano - $\mathrm{CH}_{4}$ e o dióxido de carbono - $\mathrm{CO}_{2}$ (LIMA, 2007). Sendo assim, o biogás, oriundo do tratamento dos dejetos suínos com o uso de biodigestores, pode ser transformado em energia elétrica.

A geração do biogás por meio dos biodigestores, segundo Oliveira e Higarashi (2006), pode ocorrer em três níveis de temperatura: na temperatura entre $45 \mathrm{e} 60^{\circ} \mathrm{C}$, o processo é considerado termofílico, entre 20 e $45^{\circ} \mathrm{C}$ é mesofílico, e a digestão anaeróbia de matéria orgânica em temperaturas inferiores a $20^{\circ} \mathrm{C}$ é conhecida por digestão psicrofílica. Os autores destacam que a maioria dos biodigestores anaeróbios são desenvolvidos no nível mesofílico.

Segundo Oliveira e Higarashi (2006), a eficiência de produção do biogás depende fundamentalmente da qualidade do biodigestor; do manejo do equipamento; da gestão da água no sistema de produção e, consequentemente, do percentual de matéria seca no dejeto; e até mesmo do manejo alimentar dos animais.

Lima (2007) estimou que a população brasileira de suínos gerava dejetos suficientes para se produzir cerca de quatro milhões de m3/dia de biogás. Esse biogás poderia gerar aproximadamente dois milhões de kWh de energia elétrica por dia, o que representa 60 milhões de kWh por mês. Esse estudo foi importante para fazer análises e comparações com a quantidade atual de produção do biogás que foi levantado neste trabalho.

Souza et. al. (2004) destacam que quaisquer possibilidades de geração de energia por fontes descentralizadas e em pequena escala é fundamental para o desenvolvimento sustentável, sobretudo em países com grandes extensões territoriais, como o caso do Brasil, por exemplo.

Esperancini et al. (2007) verificaram que o biodigestor gera economia considerável com a redução de uso do gás GLP, e a energia elétrica fornecida também é suficiente para a redução de uso da energia fornecida pela concessionária local. Como conclusão, foi possível verificar a viabilidade econômica da substituição das fontes convencionais de energia pelas fontes renováveis provenientes de dejetos suínos (ESPERANCINI, et al. 2007).

Cervi, Esperancini e Bueno (2010) e Freitas e Borsato (2012) defenderam a viabilidade da utilização do biogás. Concluíram que a produção do biogás é viável, mas o mal dimensionamento dos biodigestores e/ou grupo gerador pode influenciar no resultado final, corroborando com o que já tinha sido estudado por Andrade et al. (2002), onde ressaltaram que apesar das vantagens apresentadas na implantação dos biodigestores nas propriedades rurais, os resultados obtidos podem ficar abaixo do esperado se houver erros de dimensionamento dos projetos, além dos erros com operação e/ou manutenção das instalações.

IGepec, Toledo, v. 24, n.1, p. 91-115, jan./jun. 2020. 
Coldebella et al. (2008) mostraram a importância do uso dos dejetos suínos como uma fonte renovável de energia elétrica. Segundo eles, a viabilidade econômica de implantação do sistema está diretamente ligada a quantidade de energia elétrica a ser produzida. Mesmo com valores elevados de investimento, ainda é muito vantajoso explorar essa forma de energia renovável, pois a fazenda que produz suínos (objeto de seus estudos) produz dejetos suficientes tanto para produção de biofertilizantes, como do biogás. Portanto, eles concluem que instalação de biodigestores em propriedades rurais pode se tornar uma fonte de renda extra, pois além da geração de energia elétrica, a propriedade pode explorar o mercado de biofertilizantes.

Dias et al., (2013) e Sônego, Bílio e Silva (2013) corroboram com os estudos anteriores, e mostram que há viabilidade da implantação de biodigestores em granjas de pequeno porte, com a finalidade de produzir biogás a partir de dejetos suínos.

Silva (2013) também mostrou que além de diminuir os impactos ambientais da exploração da atividade de suinocultura, essa tecnologia pode render bons frutos aos produtores de suínos, tanto pela geração de energia elétrica, como com a produção de biofertilizantes.

Leite e Souza (2015) e Leitão e Silva (2018) relatam as vantagens do biogás como fonte de energia renovável, visto que no Brasil a geração de energia elétrica é basicamente feita a partir dos recursos hídricos existentes. Relatam que com o passar do tempo, os períodos chuvosos estão se alterando, e com isso, o nível das represas está cada vez mais baixos, fazendo com que o país seja obrigado a utilizar as termelétricas. Esse tipo de usina tem o custo elevado, além de ser mais poluente. Embora seja possível a comercialização, Martins e Oliveira (2011) relatam ser mais vantajoso o uso da energia na propriedade rural, substituindo ou reduzindo a aquisição da energia elétrica distribuída pela concessionária.

Martins e Oliveira (2011) mostram que a biodigestão é uma ótima forma de geração de renda para os produtores de suínos. Em estudo realizado em fazendas produtoras de suínos em Santa Catarina, pôde ser observado que essa é uma alternativa, pois não há como se utilizar os dejetos como fertilizante orgânico. Destarte, a solução apresentada soluciona parte dos problemas ambientais e ainda gera renda aos produtores. Porém, devido ao tamanho das granjas estudadas, cada uma terá um projeto e tempos de retorno diferente. Também foi analisada a volatilidade do mercado de suinocultura, podendo interferir diretamente no prazo de retorno do investimento (MARTINS; OLIVEIRA, 2011).

3.3 Potencial energético dos dejetos de suínos em biogás - Resultados das entrevistas com as empresas produtoras de motores

As informações apresentadas neste capítulo trazem resultados de coletas de dados em fontes primárias junto a empresas produtoras de motores que transformam o biogás em energia elétrica.

Geograficamente, as granjas de suínos no Brasil se concentram na região Sul, detendo 60\% das matrizes tecnificadas alojadas, com o estado de Santa Catarina como o principal produtor. A região Sudeste também é destaque neste segmento (ABCS, 2011).

Não há fontes seguras recentes sobre as matrizes alojadas no Brasil, porém, há reportagens atuais que mostram que o rebanho hoje está próximo de $\mathbf{1 . 7 0 0 . 0 0 0}$ matrizes tecnificadas. 
O Brasil registrou no ano de 2014 um crescimento no rebanho suíno de 3,2\%, chegando a um total 37,93 milhões de cabeças, o $4^{\circ}$ maior produtor de suínos, ficando atrás apenas da China, União Europeia e Estados Unidos. (IBGE, 2014)

O potencial energético da suinocultura brasileira pode ser mensurado a partir da produção dos efluentes e do biogás gerado com a instalação de biodigestores em sistemas de produção de suínos. De acordo com Souza et. al. (2004), cada matriz suína em ciclo completo gera 72 litros de dejetos/dia, cujo potencial de geração de biogás é de $0,775 \mathrm{~m}^{3} /$ dia. Dados levantados na pesquisa de campo mostram que chegaram ao total de $1,2 \mathrm{~m}^{3} /$ dia por matriz em ciclo completo. Vale lembrar que a eficiência de produção do biogás vai depender da qualidade do biodigestor; do manejo do equipamento; da gestão da água no sistema de produção e, consequentemente, do percentual de matéria seca no dejeto; e até mesmo do manejo alimentar dos animais.

O poder calorífico do biogás é de $6,5 \mathrm{KWh} / \mathrm{m}^{3}$ e a eficiência de conversão do biogás em energia elétrica com grupos geradores (motores ciclo Otto) é de aproximadamente 25\% (CCE, 2010). Importante ressaltar que a tecnologia predominante na geração de energia elétrica a partir do biogás tem eficiência de apenas 25\% (motores ciclo Otto) e que a disseminação de novas tecnologias, como é o caso da utilização de turbinas movidas pelo vapor gerado na queima do biogás, aumenta substancialmente o potencial energético da suinocultura.

Segundo Angonese, Campos e Welter (2007) o processamento dos dejetos por biodigestão com a respectiva queima dos gases se valida como um mecanismo de desenvolvimento limpo, podendo corresponder à redução de emissão de 0,54 toneladas de $\mathrm{CO} 2$ equivalentes por animal ao ano. O processo de biodigestão ocorre no interior de um biodigestor, que é uma estrutura formada por uma câmara fechada em que é colocado o material orgânico para decomposição. Pode ser um tanque revestido e coberto por manta impermeável, o qual, com exceção dos tubos de entrada e saída, é totalmente vedado, criando um ambiente anaeróbio (sem a presença de oxigênio) (OLIVEIRA et al., 2011).

Em biodigestores bem manejados a eficiência de produção de biogás está entre o,35 e o,60 m3 de biogás por m3 de biomassa, e recomenda-se que em regiões frias (Sul do Brasil) seja feito o aquecimento da biomassa e o isolamento térmico dos reatores, pois os microrganismos produtores de metano são sensíveis às variações de temperatura o que pode reduzir a produção de metano nas épocas frias do ano (OLIVEIRA; HIGARASHI, 2006).

A composição do biogás varia de acordo com a natureza da matéria-prima fermentada, e ao longo do processo de fermentação, compõe-se de metano, com teores de 55 a 75\%, e gás carbônico, principalmente com traços de diversos outros gases, como nitrogênio, hidrogênio, gás sulfídrico e oxigênio.

As opções de uso direto de biogás podem representar a única alternativa em determinadas condições e/ou circunstancias da granja. Entre as opções estão o aquecimento dos animais (leitões de maternidade, creche, crescimento e wean-tofinish), o uso doméstico na cozinha (granja e residências), uso doméstico no aquecimento da água do banho (granja e residências), uso industrial no aquecimento da água de lavagem das instalações, uso doméstico e industrial no aquecimento da água da lavanderia, uso em secadores de grãos ou caldeiras de fábrica de rações, devendo o excedente sempre ser queimado via flare (queimador).

A geração de energia a partir do biogás pode ser motriz, via motores de combustão, podendo ser utilizados em veículos automotivos (força motriz para substituição do óleo diesel, gasolina e álcool), ou para a força motriz de acionamento de motor-gerador elétrico, ou ainda, de maneira direta, a combustão em caldeiras para 
o aquecimento de massa de ar ou líquidos para o condicionamento térmico, fornecimento de calor de caldeiras e ambiente.

Os motores geradores são encontrados em diversas granjas, configurando sistemas já consolidados em algumas propriedades com motores antigos e novos, mais eficientes e confiáveis. Sua instalação exige um abrigo adequado que, em determinadas circunstâncias, deve prever a necessidade de redução do ruído para o bem-estar de animais e trabalhadores.

Segundo entrevistas com as empresas foi constatado que, independentemente da biomassa geradora do biogás (ETEs, dejetos de animais, efluentes industriais orgânicos, etc.), o que importa é a sua qualidade, ou seja, a concentração de metano e quantidade de contaminantes presentes na sua composição.

Dentro da mesma atividade suinícola, os dejetos podem apresentar diferentes concentrações e biodegradabilidade, de acordo com a composição das dietas alimentares, sistema de cultivo e de limpeza das instalações e, sobretudo, do sistema de criação adotado (SANTOS, 2000).

A produção de resíduos na suinocultura brasileira encontra-se com rebanho de 1.654.00o porcas reprodutoras em criação de leitões, onde cada animal produz o equivalente a 72 litros de chorume/dia (ABCS, 2011). Com isso, tem-se uma produção diária de aproximadamente 115 milhões de litros de dejetos (119.088 m3).

Segundo Coldebella et. al. (2008) e Santos (2000), a produção de biogás está diretamente relacionada a temperatura, uma vez que essa exerce influência na digestão anaeróbia e afeta os processos relacionados a atividade biológica dos microrganismos envolvidos.

O poder calorífico do biogás é de $6,5 \mathrm{KWh} / \mathrm{m}^{3}$ e a eficiência de conversão do biogás em energia elétrica com grupos geradores (motores Ciclo Otto) é de aproximadamente $25 \%$ (SANTOS, 2000). Importante ressaltar que a tecnologia predominante na geração de energia elétrica a partir do biogás tem eficiência de apenas 25\% (motores ciclo Otto) e que a disseminação de novas tecnologias, como é o caso da utilização de turbinas movidas pelo vapor gerado na queima do biogás, aumenta substancialmente o potencial energético da suinocultura.

Com um total de 1.654.000 matrizes e com uma potência de geração de biogás de $0,775 \mathrm{~m}^{3} /$ dia/animal, seria possível produzir $1.281 .850 \mathrm{~m}^{3} /$ dia de biogás que, dividido por 24 horas, corresponderia a 53.410,42 $\mathrm{m}^{3} /$ hora de biogás. Este valor multiplicado por $1,625 \mathrm{KWh}\left(6,5 \mathrm{KWh} / \mathrm{m}^{3}\right.$ x 0,25\%) chegaria ao total de 86.791,93 $\mathrm{KW} / \mathrm{h}$.

Com base nas teorias levantadas, e com os cálculos realizados, podemos estimar que o potencial total de geração de energia elétrica, caso fosse tratado por biodigestão anaeróbica, 100\% dos dejetos das matrizes tecnificadas brasileiras, seria de 86.791,93 $\mathrm{KW} / \mathrm{h}$.

De acordo com a Empresa de Pesquisa Energética - EPE, uma residência unifamiliar (4 a 6 pessoas) consome em média $75 \mathrm{KW} / \mathrm{h}$ (EPE, 2019). Foi possível verificar que o total de $\mathrm{KW} / \mathrm{h}$ gerados pelo tratamento dos dejetos suínos é de $86.791,93 \mathrm{KW} / \mathrm{h}$. Sendo assim, quando este valor é multiplicado por 24 horas por dia, tem-se o montante de 2.083.006,25 KW/d. Destarte, essa quantidade conseguiria abastecer $27.773(2.083 .006,25 / 75=27.773)$ residências deste porte por mês. Caso este potencial energético seja utilizado nas propriedades rurais, o resultado é ainda mais eficiente, haja vista que não haveria perdas na distribuição.

Sendo assim, fica constatado a potencialidade da geração de energia existente a partir do tratamento de dejetos na suinocultura brasileira e posterior geração do biogás. Trata-se de uma fonte alternativa e renovável com potencial significativo de 
incorporação na matriz energética brasileira, sobretudo, para uso nas próprias propriedades agrícolas.

\subsection{ANÁLISE ECONÔMICA - INVESTIMENTOS NECESSÁRIOS}

Conforme Tabela 7, os menores investimentos são observados em projetos de biodigestor para consumo próprio (projetos 3, 7, 11, 15, 19, 23, 27, 31 e 35) quando comparados dentro de uma mesma escala. Tal comportamento está relacionado a esses projetos exigirem investimentos para aquisição de biodigestores e grupos geradores de pequena escala.

Tabela 7 - Investimentos necessários para os 36 projetos

\begin{tabular}{|c|c|c|}
\hline $\mathbf{N}^{\mathbf{0}}$ & Projeto & $\begin{array}{l}\text { Investimento } \\
\text { Total (R\$) }\end{array}$ \\
\hline 1 & $\begin{array}{c}\text { Biodigestor - Ciclo Completo } 250 \text { matrizes - Geração } \\
\text { Distribuída }\end{array}$ & $\mathrm{R} \$ 368.344,03$ \\
\hline 2 & $\begin{array}{c}\text { Biodigestor - Ciclo Completo 250 matrizes - Sem Geração } \\
\text { Distribuída }\end{array}$ & $\mathrm{R} \$ 319.384,03$ \\
\hline 3 & $\begin{array}{c}\text { Biodigestor - Ciclo Completo } 250 \text { matrizes - Consumo } \\
\text { Próprio }\end{array}$ & $\mathrm{R} \$ 68.433,00$ \\
\hline 4 & Compostagem - Ciclo Completo 250 matrizes & $\mathrm{R} \$ 262.097,60$ \\
\hline 5 & $\begin{array}{c}\text { Biodigestor - Ciclo Completo 500 matrizes - Geração } \\
\text { Distribuída }\end{array}$ & $\mathrm{R} \$ 462.047,76$ \\
\hline 6 & $\begin{array}{c}\text { Biodigestor - Ciclo Completo } 500 \text { matrizes - Sem Geração } \\
\text { Distribuída }\end{array}$ & $\mathrm{R} \$ 410.027,76$ \\
\hline 7 & $\begin{array}{c}\text { Biodigestor - Ciclo Completo } 500 \text { matrizes - Consumo } \\
\text { Próprio }\end{array}$ & $\mathrm{R} \$ 101.166,00$ \\
\hline 8 & Compostagem - Ciclo Completo 500 matrizes & $\mathrm{R} \$ 376.202,88$ \\
\hline 9 & $\begin{array}{c}\text { Biodigestor - Ciclo Completo } 1000 \text { matrizes - Geração } \\
\text { Distribuída }\end{array}$ & $\mathrm{R} \$ 592.738,73$ \\
\hline 10 & $\begin{array}{c}\text { Biodigestor - Ciclo Completo } 1000 \text { matrizes - Sem Geração } \\
\text { Distribuída }\end{array}$ & $\mathrm{R} \$ 533.578,73$ \\
\hline 11 & $\begin{array}{c}\text { Biodigestor - Ciclo Completo } 1000 \text { matrizes - Consumo } \\
\text { Próprio }\end{array}$ & $\mathrm{R} \$ 194.886,00$ \\
\hline 12 & Compostagem - Ciclo Completo 1000 matrizes & $\mathrm{R} \$ 604.607,76$ \\
\hline 13 & Biodigestor - UPL 500 matrizes - Geração Distribuída & $\mathrm{R} \$ 366.171,84$ \\
\hline 14 & Biodigestor - UPL 500 matrizes - Sem Geração Distribuída & $\mathrm{R} \$ 314.151,84$ \\
\hline 15 & Biodigestor - UPL 500 matrizes - Consumo Próprio & $\mathrm{R} \$ 60.958,91$ \\
\hline 16 & Compostagem - UPL 500 matrizes & $\mathrm{R} \$ 258.525,56$ \\
\hline 17 & Biodigestor - UPL 1000 matrizes - Geração Distribuída & $\mathrm{R} \$ 451.939,15$ \\
\hline 18 & $\begin{array}{c}\text { Biodigestor - UPL } 1000 \text { matrizes - Sem Geração } \\
\text { Distribuída }\end{array}$ & $\mathrm{R} \$ 392.779,15$ \\
\hline 19 & Biodigestor - UPL 1000 matrizes - Consumo Próprio & $\mathrm{R} \$ 86.217,82$ \\
\hline 20 & Compostagem - UPL 1000 matrizes & $\mathrm{R} \$ 369.058,80$ \\
\hline 21 & Biodigestor - UPL 2000 matrizes - Geração Distribuída & $\mathrm{R} \$ 806.140,68$ \\
\hline 22 & $\begin{array}{c}\text { Biodigestor - UPL } 2000 \text { matrizes - Sem Geração } \\
\text { Distribuída }\end{array}$ & $\mathrm{R} \$ 763.300,68$ \\
\hline 23 & Biodigestor - UPL 2000 matrizes - Consumo Próprio & $\mathrm{R} \$ 164.989,64$ \\
\hline
\end{tabular}




\begin{tabular}{c|c|c}
\hline 24 & Compostagem - UPL 200o matrizes & $\mathrm{R} \$ 590.125,28$ \\
\hline 25 & $\begin{array}{c}\text { Biodigestor - Unidade de Terminação 500 animais - } \\
\text { Geração Distribuída }\end{array}$ & $\mathrm{R} \$ 237.548,21$ \\
\hline 26 & $\begin{array}{c}\text { Biodigestor - Unidade de Terminação 500 animais - Sem } \\
\text { Geração Distribuída }\end{array}$ & $\mathrm{R} \$ 187.568,21$ \\
\hline 27 & $\begin{array}{c}\text { Biodigestor - Unidade de Terminação 500 animais - } \\
\text { Consumo Próprio }\end{array}$ & $\mathrm{R} \$ 47.144,40$ \\
\hline 28 & Compostagem - Unidade de Terminação 500 animais & $\mathrm{R} \$ 169.618,88$ \\
\hline 29 & $\begin{array}{c}\text { Biodigestor - Unidade de Terminação 1500 animais - } \\
\text { Geração Distribuída }\end{array}$ & $\mathrm{R} \$ 331.686,05$ \\
\hline 30 & $\begin{array}{c}\text { Biodigestor - Unidade de Terminação 1500 animais - Sem } \\
\text { Geração Distribuída }\end{array}$ & $\mathrm{R} \$ 282.114,05$ \\
\hline 31 & $\begin{array}{c}\text { Biodigestor - Unidade de Terminação 1500 animais - } \\
\text { Consumo Próprio }\end{array}$ & $\mathrm{R} \$ 48.613,20$ \\
\hline 32 & Compostagem - Unidade de Terminação 1500 animais & $\mathrm{R} \$ 213.260,65$ \\
\hline 33 & $\begin{array}{c}\text { Biodigestor - Unidade de Terminação 4000 animais - } \\
\text { Geração Distribuída }\end{array}$ & $\mathrm{R} \$ 484.730,93$ \\
\hline 34 & $\begin{array}{c}\text { Biodigestor - Unidade de Terminação 4000 animais - Sem } \\
\text { Geração Distribuída }\end{array}$ & $\mathrm{R} \$ 421.378,73$ \\
\hline 35 & $\begin{array}{c}\text { Biodigestor - Unidade de Terminação 400o animais - } \\
\text { Consumo Próprio }\end{array}$ & $\mathrm{R} \$ 56.830,11$ \\
\hline 36 & Compostagem - Unidade de Terminação 4000 animais & $\mathrm{R} \$ 322.365,08$ \\
\hline
\end{tabular}

Os maiores investimentos entre os projetos de biodigestão são nas projeções de UPL com 2.000 matrizes (projetos 21 e 22), considerando que nestes é utilizado um gerador de $330 \mathrm{kVa}$ (gerador de maior escala entre todos os projetos de biodigestão). Da mesma forma as projeções de UT para 500 animais apresentam os menores valores de investimento necessário por exigirem biodigestores e geradores de menor porte. Vale destacar que UT produzem menores volumes de dejetos.

Projetos que envolvem geração distribuída apresentam um maior valor necessário de investimento quando comparados com seus equivalentes sem utilização de geração distribuída. Tal fato está relacionado à geração distribuída demandar investimentos adicionais em painéis de proteção e de gerenciamento exigências das concessionárias seguindo regras da ANEEL.

Entre os projetos de compostagem os maiores investimentos são observados para granjas de Ciclo Completo de 1.000 matrizes e UPL de 2.000 matrizes (projetos 12 e 24 respectivamente). A implantação da compostagem nesses projetos exige um maior montante de recursos, pois apresentam a necessidade de construção de galpões de alvenaria de maior escala, além do custeio associado do $1^{0}$ ano serem superior ao das outras projeções (apresentam maior necessidade de mão de obra, maior valor de seguro, maior gasto com energia elétrica e maior gasto com aquisição da maravalha).

\subsection{ANÁLISE ECONÔMICA - INDICADORES ECONÔMICOS}

Conforme Tabela 8, dentro das premissas adotadas, os indicadores econômicos demonstraram:

Tabela 8 - Resultado dos projetos

\begin{tabular}{c|c|c|c|c}
\hline No $^{\circ}$ & Projeto & TIR & Payback \\
\hline
\end{tabular}




\begin{tabular}{|c|c|c|c|c|}
\hline 1 & $\begin{array}{l}\text { Biodigestor - Ciclo Completo } 250 \\
\text { matrizes - Geração Distribuída }\end{array}$ & $\begin{array}{c}-\mathrm{R} \$ \\
487.281,15\end{array}$ & - & 19 anos \\
\hline 2 & $\begin{array}{c}\text { Biodigestor - Ciclo Completo 250 } \\
\text { matrizes - Sem Geração Distribuída }\end{array}$ & $\begin{array}{c}-\mathrm{R} \$ \\
386.998,10\end{array}$ & - & 19 anos \\
\hline 3 & $\begin{array}{l}\text { Biodigestor - Ciclo Completo } 250 \\
\text { matrizes - Consumo Próprio }\end{array}$ & $\begin{array}{c}-\mathrm{R} \$ \\
21.405,85 \\
\end{array}$ & $-7,04 \%$ & 11 anos \\
\hline 4 & $\begin{array}{c}\text { Compostagem - Ciclo Completo } 250 \\
\text { matrizes }\end{array}$ & $\begin{array}{c}-\mathrm{R} \$ \\
128.856,79\end{array}$ & - & 13 anos \\
\hline 5 & $\begin{array}{l}\text { Biodigestor - Ciclo Completo } 500 \\
\text { matrizes - Geração Distribuída }\end{array}$ & $\begin{array}{c}-\mathrm{R} \$ \\
343.269,42\end{array}$ & - & 16 anos \\
\hline 6 & $\begin{array}{c}\text { Biodigestor - Ciclo Completo } 500 \\
\text { matrizes - Sem Geração Distribuída }\end{array}$ & $\begin{array}{c}-\mathrm{R} \$ \\
236.718,68 \\
\end{array}$ & - & 14 anos \\
\hline 7 & $\begin{array}{l}\text { Biodigestor - Ciclo Completo } 500 \\
\text { matrizes - Consumo Próprio }\end{array}$ & $\mathrm{R} \$ 30.311,37$ & $16,46 \%$ & 4 anos \\
\hline 8 & $\begin{array}{c}\text { Compostagem - Ciclo Completo } 500 \\
\text { matrizes }\end{array}$ & $\begin{array}{c}-\mathrm{R} \$ \\
85.076,28\end{array}$ & $-0,47 \%$ & 11 anos \\
\hline 9 & $\begin{array}{l}\text { Biodigestor - Ciclo Completo } 1000 \\
\text { matrizes - Geração Distribuída }\end{array}$ & $\begin{array}{c}-\mathrm{R} \$ \\
43 \cdot 790,96 \\
\end{array}$ & $4,90 \%$ & 5 anos \\
\hline 10 & $\begin{array}{l}\text { Biodigestor - Ciclo Completo } 1000 \\
\text { matrizes - Sem Geração Distribuída }\end{array}$ & $\mathrm{R} \$ 77.384,39$ & $12,03 \%$ & 5 anos \\
\hline 11 & $\begin{array}{l}\text { Biodigestor - Ciclo Completo } 1000 \\
\text { matrizes - Consumo Próprio }\end{array}$ & $\mathrm{R} \$ 88.662,04$ & $20,30 \%$ & 4 anos \\
\hline 12 & $\begin{array}{c}\text { Compostagem - Ciclo Completo } 1000 \\
\text { matrizes }\end{array}$ & $\begin{array}{c}\mathrm{R} \$ \\
378.627,05\end{array}$ & $25,72 \%$ & 3 anos \\
\hline 13 & $\begin{array}{c}\text { Biodigestor - UPL 500 matrizes - } \\
\text { Geração Distribuída }\end{array}$ & $\begin{array}{c}-\mathrm{R} \$ \\
347.932,40\end{array}$ & - & 19 anos \\
\hline 14 & $\begin{array}{l}\text { Biodigestor - UPL 500 matrizes - Sem } \\
\text { Geração Distribuída }\end{array}$ & $\begin{array}{c}-\mathrm{R} \$ \\
241.381,66\end{array}$ & - & 16 anos \\
\hline 15 & $\begin{array}{c}\text { Biodigestor - UPL 50o matrizes - } \\
\text { Consumo Próprio }\end{array}$ & -R\$ 6.096,93 & $3,84 \%$ & 5 anos \\
\hline 16 & Compostagem - UPL 500 matrizes & $\begin{array}{c}-\mathrm{R} \$ \\
138.639,04 \\
\end{array}$ & - & 13 anos \\
\hline 17 & $\begin{array}{c}\text { Biodigestor - UPL } 1000 \text { matrizes - } \\
\text { Geração Distribuída }\end{array}$ & $\begin{array}{c}-\mathrm{R} \$ \\
141.639,69 \\
\end{array}$ & $-6,75 \%$ & 11 anos \\
\hline 18 & $\begin{array}{c}\text { Biodigestor - UPL } 1000 \text { matrizes - } \\
\text { Sem Geração Distribuída }\end{array}$ & $\begin{array}{c}-\mathrm{R} \$ \\
20.463,69\end{array}$ & $5,68 \%$ & 5 anos \\
\hline 19 & $\begin{array}{l}\text { Biodigestor - UPL 100o matrizes - } \\
\text { Consumo Próprio }\end{array}$ & $\mathrm{R} \$ 60.969,20$ & $26,37 \%$ & 3 anos \\
\hline 20 & Compostagem - UPL 1000 matrizes & $\mathrm{R} \$ 43.246,25$ & $11,51 \%$ & 5 anos \\
\hline 21 & $\begin{array}{l}\text { Biodigestor - UPL } 2000 \text { matrizes - } \\
\text { Geração Distribuída }\end{array}$ & $\begin{array}{c}\mathrm{R} \$ \\
595.214,29 \\
\end{array}$ & $26,84 \%$ & 3 anos \\
\hline 22 & $\begin{array}{c}\text { Biodigestor - UPL } 2000 \text { matrizes - } \\
\text { Sem Geração Distribuída }\end{array}$ & $\begin{array}{c}\mathrm{R} \$ \\
679.033,97\end{array}$ & $30,15 \%$ & 3 anos \\
\hline 23 & $\begin{array}{c}\text { Biodigestor - UPL } 2000 \text { matrizes - } \\
\text { Consumo Próprio }\end{array}$ & $\begin{array}{c}\mathrm{R} \$ \\
149.897,70\end{array}$ & $30,55 \%$ & 3 anos \\
\hline 24 & Compostagem - UPL 2000 matrizes & $\begin{array}{c}\mathrm{R} \$ \\
355.521,74\end{array}$ & $25,13 \%$ & 3 anos \\
\hline 25 & $\begin{array}{l}\text { Biodigestor - Unidade de Terminação } \\
500 \text { animais - Geração Distribuída }\end{array}$ & $\begin{array}{c}-\mathrm{R} \$ \\
345 \cdot 408,46\end{array}$ & - & 19 anos \\
\hline
\end{tabular}




\begin{tabular}{|c|c|c|c|c|}
\hline 26 & $\begin{array}{c}\text { Biodigestor - Unidade de Terminação } \\
500 \text { animais - Sem Geração Distribuída }\end{array}$ & $\begin{array}{c}-\mathrm{R} \$ \\
243.036,19\end{array}$ & - & 19 anos \\
\hline 27 & $\begin{array}{c}\text { Biodigestor - Unidade de Terminação } \\
500 \text { animais - Consumo Próprio }\end{array}$ & $\begin{array}{c}-\mathrm{R} \$ \\
73.451,00\end{array}$ & - & 19 anos \\
\hline 28 & $\begin{array}{l}\text { Compostagem - Unidade de } \\
\text { Terminação 500 animais }\end{array}$ & $\begin{array}{c}-\mathrm{R} \$ \\
280.725,61\end{array}$ & - & 19 anos \\
\hline 29 & $\begin{array}{l}\text { Biodigestor - Unidade de Terminação } \\
1500 \text { animais - Geração Distribuída }\end{array}$ & $\begin{array}{c}-\mathrm{R} \$ \\
278.603,40\end{array}$ & - & 17 anos \\
\hline 30 & $\begin{array}{c}\text { Biodigestor - Unidade de Terminação } \\
1500 \text { animais - Sem Geração } \\
\text { Distribuída }\end{array}$ & $\begin{array}{c}- \\
\mathrm{R} \$ 177.066,81\end{array}$ & - & 14 anos \\
\hline 31 & $\begin{array}{l}\text { Biodigestor - Unidade de Terminação } \\
1500 \text { animais - Consumo Próprio }\end{array}$ & $\begin{array}{c}-\mathrm{R} \$ \\
30.233,06\end{array}$ & - & 14 anos \\
\hline 32 & $\begin{array}{l}\text { Compostagem - Unidade de } \\
\text { Terminação } 1500 \text { animais }\end{array}$ & $\begin{array}{c}-\mathrm{R} \$ \\
206.271,53 \\
\end{array}$ & - & 19 anos \\
\hline 33 & $\begin{array}{l}\text { Biodigestor - Unidade de Terminação } \\
4000 \text { animais - Geração Distribuída }\end{array}$ & $\begin{array}{c}\mathrm{R} \$ \\
172.805,68\end{array}$ & $18,14 \%$ & 4 anos \\
\hline 34 & $\begin{array}{c}\text { Biodigestor - Unidade de Terminação } \\
4000 \text { animais - Sem Geração } \\
\text { Distribuída } \\
\end{array}$ & $\begin{array}{c}\mathrm{R} \$ \\
252.478,37\end{array}$ & $25,13 \%$ & 3 anos \\
\hline 35 & $\begin{array}{l}\text { Biodigestor - Unidade de Terminação } \\
4000 \text { animais - Consumo Próprio }\end{array}$ & $\mathrm{R} \$ 73.617,79$ & $38,80 \%$ & 3 anos \\
\hline 36 & $\begin{array}{l}\text { Compostagem - Unidade de } \\
\text { Terminação } 4000 \text { animais }\end{array}$ & $\begin{array}{c}-\mathrm{R} \$ \\
23.143,30\end{array}$ & $4,74 \%$ & 5 anos \\
\hline
\end{tabular}

- $\quad$ Entre os projetos de tratamentos de dejetos para sistemas de produção de ciclo completo, o projeto 12 de compostagem para 1.00o matrizes apresenta os melhores resultados econômicos avaliados, com 25,72\% de TIR, e payback ocorrendo no $3^{\mathrm{O}}$ ano. Apresentam ainda viabilidade econômica os projetos 7,9 , 10 e 11 . No caso do projeto 9, que trabalha com geração distribuída, apesar da viabilidade, não apresenta atratividade, devido à TIR de 4,90\% obtida ser inferior à TMA 7,50\%. As demais projeções não demonstraram viabilidade econômica;

- $\quad$ Em relação aos projetos para Unidades de Produção de Leitões, o projeto 23 para granja com 2.000 matrizes com consumo próprio apresenta os melhores indicadores, com TIR de 30,55\%, e payback ocorrendo no $3^{\circ}$ ano. Apresentam ainda viabilidade os projetos 20 e 24 de compostagem, para 1.000 e 2.000 matrizes respectivamente, e os projetos 15, 18, 19, 21 e 22 que trabalham com escalas de biodigestores para granjas de 1.000 e 2.000 matrizes. Vale destacar que apesar da viabilidade, os projetos 15 e 18 não apresentam atratividade econômica. Não apresentaram viabilidade econômica os projetos de 13, 14, 16 e 17;

- $\quad$ Para projetos de tratamentos de dejetos para Unidades de Terminação de Suínos, os projetos de 33, 34, 35 e 36 apresentam viabilidade econômica, os quais trabalham com a maior escala projetada (4.00o animais). O projeto 36 que trabalha com compostagem, apesar da viabilidade, não demonstra atratividade. Os projetos de 25 a 32 não apresentaram viabilidade econômica.

Os projetos que demonstraram inviabilidade econômica precisam de um maior tempo para darem retorno (11 a 19 anos), extrapolando o prazo de 10 anos adotado como positivo. 
Para os projetos de biodigestão vale destacar que as projeções consideraram apenas a economia de energia para a receita, não prevendo nenhum tipo de entrada advinda do biofertilizante.

\section{CONSIDERAÇÕES FINAIS}

Constata-se o grande potencial da geração de energia elétrica em caráter renovável, por meio da utilização do biogás. Em escala mais ampla, pode tornar uma nova fonte de renda extra nas propriedades produtoras de suínos, sobretudo frente ao forte aumento do custo da energia elétrica no país, bem como garantir a autossuficiência energética da propriedade produtora de suínos.

Foi constatado que o tratamento adequado dos resíduos da suinocultura é muito rentável sob a ótica da sustentabilidade, uma vez que além de gerar renda, reduz os impactos ambientais causados pelos gases de efeito estufa. O tratamento dos resíduos além de aumentar a renda dos produtores, também ajuda na diminuição da agressão ao meio ambiente, visto que os gases provenientes desses dejetos são muito danosos, e os resíduos poluem o solo, degradando mais que outras atividades agrícolas.

As perspectivas relacionadas ao tratamento de dejetos dos animais devem atender além dos objetivos tradicionais de melhorar a qualidade do ar, do solo e da água, da saúde humana e animal, também deve incluir a recuperação de nutrientes, o aproveitamento da energia e a conservação da água. Os modelos de produção sustentáveis conduzem mudanças nos sistemas tradicionais de produção animal, além de proporcionarem incrementos de lucro a atividade através da geração de biogás e biofertilizantes.

Importante ressaltar a quantidade de casas populares que poderiam ser abastecidas a partir da transformação do biogás em energia elétrica, 27.773, que representaria uma cidade de pequeno porte. Devido às expectativas do aumento da produção de suínos no Brasil e no mundo, este potencial representa um valor considerável, pois além de diminuir os custos com energia elétrica, traz ganhos ambientais, como a não emissão de gases poluentes na atmosfera.

Portanto, os resíduos da produção de suínos, que naturalmente podem causar danos ambientais, quando devidamente tratados, podem se tornar agentes promotores da sustentabilidade ambiental e econômica da produção de suínos, notadamente no que tange à geração de energia elétrica e renda.

Em contrapartida, foi observado que são poucos os projetos que demonstram viabilidade econômica em sua implantação, capitaneados principalmente pelos altos custos do investimento inicial, sendo que os projetos com maior escala de produção foram os que apresentaram os melhores resultados. Foi identificado que há limitações econômicas para a implantação de biodigestores em pequenas escalas, notadamente pela baixa escala de produção, que inviabiliza sua implantação, capitaneada pelos altos custos do investimento inicial, que aumenta vertiginosamente seu payback.

Sendo assim, seria importante que houvesse políticas públicas voltadas para que os pequenos produtores também tivessem acesso a essa tecnologia. Destarte, emerge mais um desafio para os pequenos produtores, com escalas menores de produção, que podem adotar estratégias de se aliarem a cooperativas ou condomínios para conseguirem viabilidade de implantação de tecnologias para mitigar a emissão de GEE e, ainda, ter renda com a produção de energia elétrica. 
Recomenda-se que novos estudos sejam feitos com pequenos produtores para analisar sua realidade e avaliar a melhor alternativa para a implantação dessas tecnologias.

\section{REFERÊNCIAS}

ABCS - Associação Brasileiro dos Criadores de Suínos. Manual brasileiro de boas práticas agropecuárias na produção de suínos, 2011. Disponível em: < http://www.m2design.com.br/biribas/site/wp-content/uploads/2015/o3/MANUALSUINO-FINAL-28.pdf > . Acesso em nov. de 2018.

ANEEL - Agência Nacional de Energia Elétrica. Resolução normativa no 482, de 17 de abril de 2012. DOU de 19/04/12.

ANDRADE, M. A. N.; RANZI, T. J. D.; MUNIZ, R. N.; SILVA, L. G. S.; ELIAS, M. J. Biodigestores rurais no contexto da atual crise de energia elétrica brasileira e na perspectiva da sustentabilidade ambiental, 2002. Disponível em: < http://www.proceedings.scielo.br/pdf/agrener/n4v1/o30.pdf>. Acesso em out. de 2018.

ANGONESE, A. R.; CAMPOS, A. T.; WELTER, R. A. Potencial de redução de emissão de equivalente de carbono de uma unidade suinícola com biodigestor. Engenharia Agrícola, Jaboticabal, v. 27, n. 3, 2007.p. 648-657. Disponível em: 10.1590/So10069162007000400007

BARDIN, L. Análise de conteúdo. Lisboa: Edições 70, 1977.

BRASIL. Lei $\mathbf{n}^{\circ} \mathbf{1 0 . 4 3 8 / 2 0 0 2 . ~ D i s p o ̃ e ~ s o b r e ~ a ~ e x p a n s a ̃ o ~ d a ~ o f e r t a ~ d e ~ e n e r g i a ~}$ elétrica emergencial, recomposição tarifária extraordinária, cria o Programa de Incentivo às Fontes Alternativas de Energia Elétrica (Proinfa), a Conta de Desenvolvimento Energético (CDE). DOU de 29/04/02.

CCE - Centro para Conservação de Energia. Guia prático do biogás, 2010.

Disponível em: < http://web-resol.org/cartilhas/giz__guia_pratico_do_biogas_final.pdf $>$. Acesso em out. de 2018.

CERVI, R. G.; ESPERANCINI, M. S. T.; BUENO, O. C. Viabilidade econômica da utilização do biogás produzido em granja suinícola para geração de energia elétrica. Engenharia Agrícola, 2010 p. 831-844. Disponível em: http://dx.doi.org/10.1590/So100-69162010000500006

COLDEBELLA, A.; SOUZA, S. N. M.; FERRI P.; KOLLING, E.M. Viabilidade da geração de energia elétrica através de um motor gerador utilizando biogás da suinocultura. Informe Gepec, v. 12, n. 2, 2008. Disponível em: http://erevista.unioeste.br/index.php/gepec/article/view/2186/1698 
CONAB - Companhia Nacional de Abastecimento. Planilha custo de produção suínos: série histórica, suínos, 2014. Disponível em:

<http://www.conab.gov.br/conteudos.php?a=1562\&t=2> Acesso em: jul. de 2018.

CRONIN, P.; RYAN, F; COUGHLAN, M. Undertaking a literature review: a step-bystep approach. Britsh Journal of Nursing, v. 17, n.1, p.38-43, 2008. Disponível em: 10.12968/bjon.2008.17.1.28059

LEITÃO, F.O.; SILVA, W. H. Geração de energia e renda a partir do tratamento dos resíduos da suinocultura. Informe Gepec, v. 22, p. 116-132, 2018. Disponível em: http://e-revista.unioeste.br/index.php/gepec/article/viewFile/18024/12838

DIAS, M. I. A.; COLEN, F.; FERNANDES, L. A.; SOUZA, R. M.; BUENO, O. C. Viabilidade econômica do uso do biogás proveniente da suinocultura, em substituição a fontes externas de energia. Revista Energia na Agricultura, Botucatu, vol. 28, n.3, 2013. p.155-164. Disponível em: file://C:/Users/Fabricio/Downloads/767Texto\%20do\%20artigo-4789-2-10-20131219.pdf

EPE - Empresa de Pesquisa Energética. Demanda de Energia. Disponível em: $<$ http://epe.gov.br/sites-pt/publicacoes-dadosabertos/publicacoes/PublicacoesArquivos/publicacao-332/topico424/02\%20Demanda\%20de\%20Energia_Texto.pdf\#search=resid\%C3\%AAncia\%20 popular > . Acesso em 02 de abril de 2019.

ESPERANCINI, M. S. T.; COLEN. F.; BUENO, O. C. B.; PIMENTEL, A. E. B.; SIMON, E. J. Viabilidade técnica e econômica da substituição de fontes convencionais de energia por biogás em assentamento rural do Estado de São Paulo. Engenharia Agrícola, Jaboticabal, v.27, n.1, 2007. p.110-118, jan./abr. Disponível em: http://dx.doi.org/10.1590/So100-69162007000100004

FREITAS, G. S.; BORSATO, J. M. L. S. Um estudo sobre a utilização de biogás como fonte de energia renovável de energia em uma fazenda de criação de porcos. In: XXI Encontro Nacional de Geografia Agrária. Uberlândia, 15 a 19 de out. de 2012.

GERBER, P.J.; STEINFELD, H.; HENDERSON, B.; MOTTET, A.; OPIO, C.; DIJKMAN, J.; FALCUCCI, A.; TEMPIO, G. 2013. Tackling climate change through livestock: A global assessment of emissions and mitigation opportunities. Food and Agriculture Organization of the United Nations (FAO), Rome, 2013.

LEITE, D. B.; SOUZA, Ê. P. Tendências do cenário energético brasileiro: a energia de fonte eólica e o "olhar" dos atingidos. Ciência e Natura, v. 37, n. 3, p. 243-250, 2015. Disponível em: http://dx.doi.org/105902/2179460X17322

LIMA, P. C. R. Biogás da suinocultura: Uma importante fonte de geração de energia. Biblioteca Digital da Câmara dos Deputados, 2007. Disponível em: file://C:/Users/Fabricio/Downloads/biogas_suinoculltura_lima.pdf

MARTINS, F. M.; OLIVEIRA, P. A. V. Análise econômica da geração de energia elétrica a partir do biogás na suinocultura. Engenharia Agrícola, Jaboticabal, v. 31, 
n. 3, p. 477-486, 2011. Disponível em: http://dx.doi.org/10.1590/So10o69162011000300008

OLIVEIRA, P. A. V.; HIGARASHI, M. M. Geração e utilização de biogás em unidades de produção de suínos. Concórdia: Embrapa Suínos e Aves. 2006. (Série Documentos DOC-115). Disponível em:

https://ainfo.cnptia.embrapa.br/digital/bitstream/item/58216/1/doc115.pdf

SANTOS, P. Guia técnico de biogás. CCE - Centro para a Conservação de Energia. Guia Técnico de Biogás. AGEEN - Agência para a Energia, Amadora, Portugal, p.117, 2000. Disponível em:

http://www.scielo.br/scielo.php?script=sci_nlinks\&ref=000185\&pid=So1006916201000050000600016\&lng=pt

SILVA, H. W. A tecnologia da biodigestão anaeróbica na produção de biogás gerado por dejetos de suínos. Revista Brasileira de Agropecuária Sustentável, v.3, n.1, 2013. p.55-60.

SÔNEGO, D. A.; BÍLIO, R. S.; SILVA, E. F. Viabilidade econômica e otimização do uso do biogás de suinocultura. In: IV Congresso Brasileiro de Gestão Ambiental, Salvador, BA, 25 a 28 de nov. de 2013.

SOUZA, S. N. M.; PEREIRA, W.C.; NOGUEIRA, C. E. C.; PAVAN, A. A.; SORDI, A. Custo da eletricidade gerada em conjunto motor gerador utilizando biogás da suinocultura. Technology Acta Scientiarum, v. 26, n. 2, p. 127-133, 2004. Disponível em: 10.4025/actascitechnol.v26i2.1510 


\author{
Submetido em 28/o9/2019 \\ Aprovado em 20/3/2020
}

\title{
Sobre o(s) Autor(es):
}

\section{Fabrício Oliveira Leitão}

Possui graduação em Administração, especialização em Gestão Educacional, mestrado em Agronegócios, e doutorado em Transportes. Atualmente é professor da Faculdade CNEC Unaí, titular das disciplinas de Teorias da Administração, Administração da Produção e Operações, Introdução à Engenharia de Produção, Desenvolvimento do Produto e Logística. Professor no UDF Centro Universitário de Brasília, lecionando as disciplinas de Gestão de Projetos, Análise e Melhoria de Processos, Arquitetura Organizacional e Gestão da Produção e Operações. Também é coordenador do curso de Engenharia de Produção da Faculdade CNEC Unaí, e supervisor da Revista CNEC com Ciência. Tem artigos publicados em Revistas Especializadas trabalhando com as linhas de pesquisa voltadas para a Gestão da Produção e Logística. É membro do grupo de pesquisa do GPIT/UnB (Grupo de Pesquisa sobre Planejamento e Gestão em Transportes) e do GECOMP/UnB (Grupo de Estudos sobre a Sustentabilidade e Competitividade do Agronegócio/UnB) onde lidera uma linha de pesquisa sobre Logística no Agronegócio. Foi consultor do Ministério da Agricultura, Pecuária e Abastecimento no projeto Suinocultura de Baixa Emissão de Carbono em 2015 e 2016. Email: fabriciofol@hotmail.com

\section{Cleandro Pazinato Dias}

Graduação em Medicina Veterinária pela Universidade Federal de Santa Maria - UFSM (1994). Mestrado em Ciências Veterinárias pela Universidade Federal do Rio Grande do Sul (UFRGS) na área de Reprodução Animal (2000). MBA em Gestão em Agribusiness pela Fundação Getúlio Vargas - FGV (2006). Doutorado em Ciência Animal pela Universidade Estadual de Londrina ? UEL, com período sanduíche na Universidade Autônoma de Barcelona (UAB), desenvolvendo projetos na área de bemestar animal (2014). Com experiência em suínos, atuando em empresas de consultoria, genética e nutrição na implantação e gerenciamento de projetos suinícolas independentes e integrados. Consultor do Instituto Interamericano de Cooperação para Agricultura (IICA) na área de sustentabilidade, desenvolvendo em parceria com o Ministério da Agricultura Pecuária e Abastecimento (MAPA) os projetos: Suinocultura de Baixa Emissão de Carbono e Pecuária de Baixa Emissão de Carbono. Consultor do Projeto Diálogos Setoriais União Europeia - Brasil para ação: Estratégias do SVO e setor privado para adoção de gestação coletiva de matrizes suínas. Membro da OIE ad hoc Group on Animal Welfare and Pig Production Systems. Email: cleandropadias@hotmail.com

\section{Marlon Vinícius Brisola}

Pós-doutor pela Facultad de Ciencias Económicas, Universidad de Buenos Aires, Argentina (Tit Projeto: El Estado y el agronegocio de la carne vacuna: un analisis histórico y comparado entre Argentina y Brasil), Doutor em Ciências Sociais, com especialização em estudos comparados sobre as Américas (CEPPAC/UnB), Mestre em Ciências Agrárias, com especialização em Agronegócios (UnB), Mestre em Administração de Empresas (CNEC) e Graduado em Medicina Veterinária (UFMG). Professor da Universidade de Brasília - Faculdade de Agronomia e Medicina Veterinária - Área de Ciências Sociais Aplicadas e Agronegócios. Pesquisador Credenciado do PROPAGA - Programa de Pós-graduação em Agronegócios, da UnB. Líder do Grupo de Estudos sobre a Competitividade e Sustentabilidade do Agronegócio (GECOMP/CNPq). Membro da Sociedade Brasileira de Economia, Administração e Sociologia Rural (SOBER) e do Grupo de Estudos do Mercosul (GES-UniCEUB/CNPq). Áreas de interesse: História Econômica Comparada; Desenvolvimento Regional e Institucional no âmbito dos 
Produção do conhecimento edesafios metodológicos: análise das dissertações e teses do PPG's em desenvolvimento regional

Sistemas Agroindustriais, tanto no Brasil, como na América Latina; Sociologia dos Mercados aplicada aos Agronegócios, estudos prospectivos no agronegócio. Email: mvbrisola@yahoo.com 